\title{
Chaos in Human Behavior: The Case of Work Motivation
}

\author{
José Navarro ${ }^{1}$, and Carlos Arrieta ${ }^{2}$ \\ ${ }^{1}$ Universidad de Barcelona (Spain) \\ ${ }^{2}$ Universidad de Costa Rica (Costa Rica)
}

This study considers the complex dynamics of work motivation. Forty-eight employees completed a work-motivation diary several times per day over a period of four weeks. The obtained time series were analysed using different methodologies derived from chaos theory (i.e. recurrence plots, Lyapunov exponents, correlation dimension and surrogate data). Results showed chaotic dynamics in $75 \%$ of cases. The findings confirm the universality of chaotic behavior within human behavior, challenge some of the underlying assumptions on which work motivation theories are based, and suggest that chaos theory may offer useful and relevant information on how this process is managed within organizations.

Keywords: work motivation, deterministic chaos, complexity science, diary technique.

Se realizó un estudio con el objetivo de explorar la posible dinámica caótica de la motivación en el trabajo. Cuarenta y ocho trabajadores contestaron un diario sobre su motivación en el trabajo varias veces al día durante cuatro semanas. Las series obtenidas fueron sometidas a diferentes técnicas de análisis no lineal derivadas de la teoría del caos (gráficos de recurrencia, exponentes de Lyapunov, dimensión de correlación y surrogate data). Los resultados mostraron dinámicas caóticas en un $75 \%$ de los casos. Ello confirma la universalidad del comportamiento caótico también dentro del comportamiento humano. Tales resultados cuestionan algunos de los supuestos fundamentales en los que se basan las teorías más establecidas y sugieren que la teoría del caos puede ofrecer información útil y relevante acerca de cómo gestionar la motivación en contextos laborales.

Palabras clave: motivación en el trabajo, caos determinista, ciencia de la complejidad, técnica del diario.

Correspondence concerning this article should be addressed to José Navarro. Facultad de Psicología. Departamento de Psicología Social. Paseo Valle de Hebrón, 171.08820 Barcelona. (Spain).E-mail: j.navarro@ub.edu 


\section{Chaos theory}

One of the things that has characterised the last two decades is the incursion of science into social life. Indeed, many scientific findings are reported in newspapers or on television news and specialist journals such as Nature or Science are now well known and purchased by the general public. In this context, one of the scientific discoveries to have gone beyond academic borders and reached the general public is the discovery of deterministic chaos.

Discovered largely by chance, and as Lorenz $(1993 / 1995)$ points out, the theory of deterministic chaos has served to underpin two important epistemological principles in the world of science (Tsonis, 1992): firstly, that aperiodic behavior similar to random behavior is observed in numerous phenomena (i.e. the movements of a flag unfurled in the wind) and can be the product of deterministic rules; and secondly, that a phenomenon showing nonlinear behavior should be treated as such and not simplified or approached as if it were a linear phenomenon.

Deterministic chaos can be understood as "aperiodic bounded dynamics in a deterministic system with sensitive dependence on initial conditions" (Kaplan \& Glass, 1995: 27). Systems with chaotic dynamics share the following features (Mathews, White \& Long, 1999): firstly, they show aperiodicity, that is, they are systems whose dynamics never pass twice through the same state; secondly, the dynamic behavior of the system stays within a finite range of values, after which it is self-contained; thirdly, the dynamic is deterministic, that is, it is regulated by rules; and fourthly, the system shows sensitive dependence on initial conditions, in other words, two starting points, no matter how close together, will give rise to very different evolutions of the system. This last aspect is also known as the "butterfly effect", one which is more widely known among the general public. Furthermore, it is possible to derive from this fourth aspect a premise of important scope concerning the issue of proportionality. In other words, those often small and almost imperceptible disruptions are capable of generating significant changes in a phenomenon's behavior in the long term.

In addition to the above the last twenty years have also been fruitful in terms of the development and improvement of tools for identifying and measuring deterministic chaos. Scientists now have at their disposal graphical procedures (i.e. recurrence plots or delay graphs) and quantitative indexes (i.e. Lyapunov exponents or the correlation dimension) which allow them to characterize a system as chaotic (cf. Heath, 2000).

Given the above it is no surprise that several authors from different disciplines have sought to identify and measure chaotic dynamics. As a result, we now know (cf. Cvitanovic, 1989) that chaotic behavior can be found among many different phenomena, whether these be physical (such as turbulence flow or the convection diagram of a fluid heated from below), chemical (e.g. different electric and mechanical oscillators or the oscillations within the celestial $\mathrm{X}$ ray sources), meteorological (e.g. the Earth's climate or glacier sequences in the Quaternary), ecological (e.g. population phenomena or the epidemiology of diseases such as measles, rubella or chickenpox), or biological (e.g. the cardiac rhythm of healthy individuals or the electrical activity of the brain). In short, an important variety of nonlinear systems that behave in a chaotic manner have been discovered, thus demonstrating that chaos is a more universal phenomenon than we might think. Furthermore, social sciences such as economics, business administration and social psychology have also shown increased interest in deterministic chaos, as will be discussed below.

The chaos theory has revealed the relativist and reductionist nature of some of the postulates underlying the dominant scientific paradigm in the natural and social sciences, namely logical positivism (see Munné, 2004, 2005). There are two aspects here which merit particular attention: firstly, systems that are totally deterministic are no longer totally predictable. In fact, the sensitivity to initial conditions shown by chaotic systems would require an infinite precise knowledge, which is impossible to acquire, in order to make reliable predictions. Secondly, the chaotic behavior observed in a number of physical, chemical or biological systems show low dimensionality. This means that there are only a few variables that generate the dynamic and that the complexity observed in many phenomena might be a result of simple causes.

\section{Influences in social sciences and psychology}

The challenging of these assumptions (determinism does not always entail predictability and complexity does not always have a multidimensional causality) has prompted the social sciences to look more closely at chaos theory, as most of the phenomena studied in this field are hard to predict and have shown high complexity when causal models with a small number of variables are considered. This is why in recent decades the application, whether literal or metaphorical, of this theory has been extended to the study of numerous phenomena of human and social behavior. For example, in the field of economics multiple models that consider the economy as a chaotic and complex system have been proposed (Arthur, 1999). Furthermore, several findings supporting chaotic behavior within different economic indexes have been reported (i.e. stock market, price evolution, etc.; see Dechert, 1996).

Within the field of psychology several applications have been tried, although most of them have used chaos theory as a metaphor and only a small number have employed the theory as a basis for empirical research (see, for example, Abraham \& Gilgen, 1995; Guastello, Koopmans \& Pincus, 
2009; Masterpasqua \& Perna, 1997; Robertson \& Combs, 1995; Vallacher \& Nowak, 1994). It is also true that most applications to date have involved a metaphorical use of chaos theory (in which it is proposed that a specific process might be considered and analysed as chaotic), and thus they do not contribute empirical findings in support of this idea.

In our view there are two main reasons for this. The first concerns operationality, in that it is difficult for social scientists to obtain time series that are long enough to conduct analyses and which enable deterministic chaos to be detected. The second reason is more historical and has to do with the metaphoric applications that have so far been necessary as this approach, together with other theoretical contributions to complexity science (see Munné 2005) has sought to develop a new paradigm, that of complexity theory; this has emerged as an alternative to the more positivistic paradigm and seems able to cover some of the gaps generated by the latter. Specifically those regarding the massive and indiscriminate use of cross-sectional study designs together with the application of models and techniques of linear data analyses for studying human behavior, which seldom seems to follow a linear pattern.

In recent years, chaos theory has also been applied empirically with the aim of identifying chaotic dynamics in human behavior. However, this is not an easy task as several methodological and operative aspects combine to make such studies difficult. For instance, in order to apply the more classical statistical tools proposed by chaos theory (computation of Lyapunov exponents, correlation dimension, entropy, etc.), long time series with hundreds of recordings are needed. But this is difficult to obtain, except in the case of psycho-physiological recordings which are collected automatically and without any effort being required from the participant. This is why recordings obtained from EEGs or cardiac rhythms have been widely studied, the results showing that chaotic dynamics are indeed present (Bahrami, Seyedsadjadi, Babadi \& Noroozian, 2005; Eidukaitis, Varoneckas \& Zemaityte, 2004; Stam, 2005; Yeragani et al., 2002). Another obstacle concerns the difficulty of identifying when time series present a deterministic chaotic or random pattern, which makes it necessary to use different types of analysis (such as those mentioned earlier) in order to study the coherence among them.

\section{Chaos evidences in organizational behavior}

Given these difficulties there are a number of noteworthy pioneering studies which, using either a classical procedure or some alternative procedures of analysis developed for working with shorter series, have found chaos in several aspects of human behavior. Key examples would be the studies by Richards (1990), Cheng and Van de Ven (1996), Guastello (1998), Guastello, Hyde and Odak (1998), Guastello, Johnson and Rieke (1999),
Woyshville, Lackamp, Eisegart and Gilliland (1999), Pincus (2001) and Navarro, Arrieta and Ballén (2007). Let us look more closely at some of these studies.

Richards (1990) studied various group decisionmaking processes to determine whether they followed a chaotic dynamic. Three decision-making processes were studied: the first formed part of an experimental study and concerned the decisions made by four pairs of players in a prisoner's dilemma scenario, which generated 120 interactions; the second involved political decisionmaking and used defence spending of the US government for the period 1885-1985 (series of 101 recordings) as an indicator; and the third, also of a political nature, analysed the number of written official statements issued daily by the US government during the Cuban missile crisis (no data are available for the number of recordings). By analysing the correlation dimension (method of Grassberger \& Procaccia, 1983) the author found that in five of the six series analysed (the exception being one of the pairs in the experimental study) the decision-making processes showed chaotic dynamics.

Although the research conducted by Richards is of enormous merit in that it sought as long ago as 1990 to take complexity theory as its starting point, it nevertheless suffers from certain methodological limitations, such as working without calculating the optimum values of the lag or the embedding dimension, both of which are necessary for the correct calculation of the correlation dimension.

In a later study, Cheng and Van de Ven (1996) investigated the market behavior of two biomedical innovations by analysing: 1) the decisions made by the innovation teams (with two values: actions aimed at continuation/expansion or actions aimed at contraction/ modification); 2) the results obtained (with four possible values: positive, negative, neutral and mixed); and 3) the number of contextual events relevant to the innovation process. All the data were collected on a monthly basis according to an evaluation of the information made by two external judges, who showed a high degree of interrater agreement $(92 \%)$. The three data series obtained were divided into two periods, the cut-off point being the date on which the proposed innovation entered the market. Structured in this way the size of the series analysed was as follows: 102 recordings (first innovation, first phase), 50 (first innovation, second phase), 74 (second innovation, first phase) and 22 (second innovation, second phase). The authors then applied three types of analysis (calculation of the Lyapunov exponents (algorithm of Wolf, Swinney \& Vastano, 1985), the correlation dimension (method of Grassberger \& Procaccia, 1983) and the BDS statistic to the first three series (the fourth had an insufficient number of data) and found that the biomedical innovations showed chaotic dynamics in their initial phases, prior to market entry, with respect to actions and results; however, this was not the case for contextual events, which showed 
random behavior. It should be noted that the findings of this study are not conclusive for two reasons: firstly, some contradictory results were obtained when comparing the BDS statistic with the other analyses; and secondly, neither the optimum value of the lag nor that of the embedding dimension were taken into account.

Nevertheless, the findings of Cheng and Van de Ven are largely consistent with those reported by Guastello (1998) and Guastello et al. (1998). These authors studied creative problem solving in small groups by analysing aspects such as the number of interactions per time interval, the number of discussions that were simultaneously both active and different, and the total amount of interaction. The results revealed positive Lyapunov values and low correlation dimensions (value of 1.46). For both statistics the authors used algorithms that were generated ad hoc.

In a subsequent study Guastello et al. (1999) took a group of 24 undergraduates and looked at the evolution over time of their experiences of motivational flow, where this is understood as an experience of intrinsic motivation characterised by intense involvement in an activity on the part of the subject. In this specific study the experiences recorded included both work and leisure activities. Using the diary technique each participant recorded over a period of a week the type of activity performed (according to a previously established classification system), its duration, the level of challenge it implied, and their opinion regarding the skills level required to carry it out correctly (these latter two aspects were scored on a Likert scale from 0 to 9). Using a specially-designed algorithm to calculate the Lyapunov values of the flow generated by each participant the authors found evidence of chaos in all cases. They also tested two regression models (one exponential non-linear and the other linear) in order to explain fluctuations in flow over time and found that the first of these showed a significantly better fit with the data $\left(R^{2}=.26 \mathrm{vs} . R^{2}=.05\right)$.

Similar results were also reported in the area of work motivation by Navarro et al. (2007). These authors collected information via a diary developed using variables that have long been of interest in work motivation research, i.e. selfefficacy beliefs and perceived instrumentality. Participants (a sample of twenty employees from various sectors and in different posts) completed the diary at random intervals several times a day over a period of seventeen consecutive working days. The time series obtained were subjected to various analyses, namely the correlation function, nonlinear prediction graphs and calculation of the Hurst exponent, all of which were performed using the specialist software package Chaos Data Analyzer. The results showed a high percentage of nonlinear deterministic dynamics (between $88.2 \%$ and $91.6 \%$ depending on the technique employed). Furthermore, the advantage of the procedures used in this study is that they do not require calculation of the embedding dimension, and they can work on short time series (around 50-100 recordings). Nevertheless, it should be noted that there were some inconsistencies between the different techniques used.

A final example is the study by Woyshville et al. (1999), which investigated instabilities in mood when this is analysed longitudinally. The authors used the diary technique with 63 people (37 patients with affective disorders in the experimental group and 26 people without this disorder as the control group) who were required to self-report regarding their mood state over a period of thirteen weeks, the evaluation being made on a scale of 0-100 (where $0=$ 'Lowest your mood has ever been', $50=$ 'Mood neither elevated nor low' and $100=$ 'Most elevated your mood has ever been'). The authors found a result which they themselves regarded as paradoxical, namely that patients showed significantly more variability (where variability is taken as the rate of variation from one day to the next) and significantly less complexity (or fractal dimension) than did the control group. In this case the fractal dimension was calculated using the algorithm of Russo and Mandell (1983). Another finding of this study was that the series showed fractional dimensions, which is indicative of chaotic behavior in the mood states of people in both the experimental and control groups.

Moreover, using the catastrophe theory, one of the theories that form part of the complexity science (see Munné, 2005), Guastello found evidence of nonlinearity and irregularity in different aspects of organizational behavior, such as academic performance, organizational change, group coordination and leadership emergence (for a good compilation of these studies see Guastello, 2002).

In sum, this brief review illustrates that different facets of human behavior show non-linearity and chaos, and that these complex dynamics emerge when researchers use appropriate designs (longitudinal) and techniques capable of dealing with non-linearity and irregularity. It is also noteworthy that basic processes of human behavior such as affect and motivation behave chaotically, thus lending support to the comment of Cvitanovic (1989) regarding the universality of this type of behavior.

\section{The present study}

Although the studies of Guastello et al. (1999) and Navarro et al. (2007) are pioneering in the field of work motivation, these studies have limitations in their endeavours to demonstrate the essentially chaotic nature of human motivation. In our view the study by Guastello et al. (1999) suffers from two important limitations: firstly, the sample was comprised entirely of undergraduates; secondly, and of key importance in our view, the time series were obtained by making recordings every fifteen minutes, on the assumption that the person was engaged in 
the same task and maintained the same motivational flow throughout the time in which no new task was noted; thus, the same values were assigned throughout this period.

Although the study by Navarro et al. (2007) overcomes some of the abovementioned limitations (the sample, albeit small, is varied and classical statistical techniques associated with chaos theory were used), it is hindered by the fact that a sizeable number of the time series analysed could not be conclusively categorized as nonlinear versus random. In addition, although this study is useful in terms of demonstrating that motivational dynamics may involve a variety of patterns (linear, nonlinear and random) it does not detect deterministic chaos as such, as the procedures used are designed not for this purpose but rather for determining whether the series show some kind of deterministic pattern (linear or nonlinear) or, in contrast, are random.

Given the limitations of these work motivation studies there is a need for new research that is capable of clarifying whether or not the dynamic of this phenomenon follows chaotic behavior patterns, and which does so using widely validated analytic tools. In this regard the use of alreadyvalidated techniques capable of detecting deterministic chaos, in conjunction with the surrogate data technique, should enable more conclusive results to be obtained. The choice of technique is also dependent on the size of the time series being worked with, as an important limitation of some of the techniques developed to date is that they require a series size that is hard to obtain in psychological research (500 recordings or more). More recently, however, techniques have been developed which function adequately with time series of as few as 100 recordings, which makes it more feasible, although not easy, to conduct empirical studies of psychological phenomena from the perspective of complexity science. In this regard, qualitative procedures such as recurrence plots, or statistical indices such as Lyapunov exponents and the correlation dimension may prove to be of great utility (Heath, 2000).

Given the gaps identified in research on deterministic chaos in work motivation, the present study sought to use the abovementioned techniques to explore whether this phenomenon is structured as a process with chaotic dynamics. Our aim was to contribute to the development of the complexity paradigm and promote its application in the study of organisational behavior. We believe that this could help generate significant knowledge in the field by relativising assumptions that have traditionally been regarded as firmly established and, therefore, rarely subjected to scrutiny. Indeed, as several authors have pointed out (Fried \& Slowik, 2004; George \& Jones, 2000) the most widely-used theoretical approaches to work motivation (expectancy-valence theory, goal setting theory, self-efficacy theory and theories of organisational justice) have paid very little attention to the time factor or to how work motivation evolves over time. Moreover this is despite the fact that the latest conception of work motivation sees it as a process, in other words, as something which changes and evolves over time. However, when it comes to studying this process, research has tended to take an episodic approach to the phenomenon (cf. Kanfer, 1990; Williams, Donovan \& Dodge, 2000), with little interest generally being shown in understanding how motivation behavior evolves. To date, traditional theories have largely failed to investigate what happens once a goal is met, consider the results with value, or at what point perceived justice achieves a new equilibrium. Several authors have argued that this situation has greatly hindered the progress of research in the field of work motivation, as well as in other areas of organisational behavior (cf. Ancona, Goodman \& Tushman, 2001; Ancona, Okhuysen \& Perlow, 2001; Dalal \& Hulin, 2008; McGrath \& Kelly, 1986; McGrath \& Tschan, 2004; Mitchell \& James, 2001; Mosakowski \& Early, 2000; Roe, 2005a, 2005b, Steers, Mowday \& Shapiro, 2004).

In sum, this paper describes an exploratory study that sought to determine whether or not work motivation showed chaotic dynamics, where the former is understood as an evolving process that fluctuates over time. The objective was thus to characterise these fluctuations.

\section{Method}

\section{Design and Procedure}

Given the objective of the study a longitudinal design was applied. To this end we used the diary technique, taking into account the work of Guastello et al. (1999) and Navarro et al. (2007), as well as the suggestions of Bolger, Davis and Rafaeli (2003) regarding the use of this technique. In line with the approach of these latter authors we used a time-based, signal-contingent design and the technique was chosen for two main reasons: firstly, because it enables time series to be obtained that are broad enough to ensure an adequate recording of the phenomenon's behavior over time; and secondly, because its correct use allows life to be captured as it is lived, as it examines experiences in their natural and spontaneous context, thus reducing measurement errors, especially those due to retrospection (Bolger et al., 2003; Pentland, Harvey, Lawton \& McColl, 1999).

During the study, participants completed the diary six times per day over a period of twenty working days. This period was chosen due to the need to obtain a time series of at least 100 recordings per participant, this being the minimum number required by the analyses to be conducted. Information was collected using personal digital assistants (PDAs). The diary was loaded into the PDAs and these were then programmed to emit a contingent signal at random intervals during the participants' working day, 
thus reminding them that they had to record the requested information. The random programming was used to avoid predispositions among participants, thus ensuring more natural responses and enabling us to obtain a distribution of recordings that covered most of the tasks carried out by participants in their workplace. The software used to develop the diary, install it in the PDAs and collect the information was Pendragon Forms 4.0.

Given the advantages they offer in terms of reliability (cf. Bolger et al., 2003), PDAs have been widely used in research carried out in various disciplines such as medicine, pharmacology and nursing (cf. Weber \& Beverly, 2000), and more recently they have also been introduced into the field of psychology (Scollon, Diener, Oishi \& Biswas-Diener, 2005). Their main limitation is that many people are unfamiliar with how to use them. In the present study this limitation was minimised by offering a training session aimed at instructing participants in the use of the PDA and explaining to them the instrument used (clarifying the concepts of task and personal goals; see section Instrument). A trial run was also used to check that they were using the instrument correctly and highlight any potential difficulties which might arise during the study (possible loss of data due to flat batteries, need to adjust the volume of the reminder tone according to the work context of each participant, etc.).

\section{Instrument}

Given the demands which this type of design places on participants, and with the aim of avoiding high dropout rates, the diary used consisted of a brief questionnaire similar to that employed by Navarro et al. (2007) in a previous study. This questionnaire comprised the following four questions:

1. What task am I carrying out at this moment?

2. How much does this task motivate me?

3. To what extent do I consider myself capable of performing the task well?

4. If I perform the task well, will I achieve my personal goals?

These questions cover the variables of interest in the present study. The third and fourth questions refer to fundamental processes of different theories that are currently in vogue: self-efficacy beliefs (social cognitive theory: Bandura, 1997) or the skills that individuals perceive themselves to have in relation to the activity (flow theory: Csikszentmihalyi, 1990) and perceived instrumentality (expectancy-valence theory: Vroom, 1964). The first question is also essential if we wish to investigate self-efficacy beliefs or perceived skills, as research has repeatedly shown that these are specific and relative to given tasks (cf. Stajkovic \& Luthans, 1998). Finally, the second question is included in order to address directly the level of motivation felt by the person carrying out the task.

The information collected for each of these questions was both textual (task carried out) and quantitative, through use of a slider bar whose two ends were labelled as follows: A little-A lot (for question two regarding motivation), Not very capable-Very capable (for question three on selfefficacy or perceived skills) and Unlikely-Likely (for question four about instrumentality). Participants marked the slider bar directly and the PDA system converted this mark into a score between 0 and 100 . According to the aim of this research we only use the quantitative information.

\section{Participants}

The sample comprised 48 workers from various professions and who belonged to different organisations or companies. Although we decided against working with representative samples due to this being difficult with the type of design used, we did seek to obtain a sample that, although small, was varied in terms of gender, age, profession, company and years of experience.

Of the 48 workers 25 were men and 23 women (mean age 35 years; range 20-57). Seventy-eight percent were university graduates, $66 \%$ worked in private companies, $24 \%$ in the public sector and $10 \%$ in a semi-public organisation. Of the total, $24 \%$ had a profession related to economics or business management, $10 \%$ to trade and sales, another $10 \%$ to medicine and health, and $8 \%$ to administration. The number of years working for their organisation ranged from 1 to 38 , with a mean of 8 years. Finally, participants worked on average nine hours a day, the total weekly mean being 49 hours.

All participants were recruited personally by the researchers, either directly or via third parties. The basic inclusion criteria were that participants were employed at the time of the study and willing to abide by the procedures established for data recording using the diary. Participation was voluntary and individual feedback was given at the end regarding the results obtained.

\section{Analysis}

The first step involved purifying the data obtained in order to eliminate any possible duplicate recordings (i.e. the participant completed the diary on two or more consecutive occasions without respecting the interval of at least fifteen minutes which had been programmed into the PDA). After purification the data were subjected to various standard descriptive analyses (mean, standard deviation, minimum and maximum values). The correlations between the three items were also analysed and Cronbach's alpha was calculated in order to justify the use of a common index based on the mean score on these three questions. 
All these analyses were performed using SPSS.

A motivation index was calculated by using the mean score on the three quantitative questions and these were used to develop the time series, which were then subjected to the various analyses associated with complexity theory. Given that the present study sought to explore whether or not work motivation as a whole was chaotic in nature, rather than focus on the potential chaotic dynamics of its specific components in isolation, the use of a generic indicator proved highly useful.

The next step involved producing line graphs in order to observe the irregularity in the motivation dynamics, and subsequently we drew up the recurrence plots which form one of the key analyses of this research. This was done by calculating the optimum values of both the lag and the embedding dimension, using the procedures recommended (AMI and FNN; cf. Heath, 2000). Recurrence plots are a useful tool for detecting deterministic patterns, whether linear or nonlinear, in a time series. The plot obtained shows the presence of chaos when lines appear in parallel to the main diagonal. In contrast, random dynamics show no such pattern and produce completely uniform plots, while linear dynamics show highly regular patterns. These analyses were performed using VRA (Visual Recurrence Analysis) software (cf. Belaire-Franch \& Contreras, 2002).

We also calculated two other widely-used statistics: the correlation dimension (a measure of the degree of irregularity in a time series and an indicator of dimensionality in terms of the number of variables that are determining the dynamic) and Lyapunov exponents (a measure of sensitive dependence on initial conditions). The correlation dimension was calculated with the VRA that uses the algorithm of Grassberger and Procaccia, while the Lyapunov exponents were calculated using TISEAN (Time Series Analysis; cf. Hegger, Kantz \& Schreiber, 1999), which uses the algorithm of Rosenstein, Collins and De Luca (1993), suitable for the analysis of short time series.

Finally, in order to distinguish more clearly between chaotic and random dynamics we also calculated the surrogate data series (cf. Schreiber \& Schmitz, 2000) using TISEAN. Starting from the original series this procedure enables a numerous set of new series to be generated, in which the data appear in a randomly disordered way. The predicted series calculated from the original series were then compared with the predicted series calculated from the surrogate series. If this comparison revealed no differences between the predictions from the original series and those from the surrogate series it was concluded that the dynamic was random.

\section{Results}

Firstly, let us consider the descriptive results of the time series. Table 1 shows the means, standard deviations and minimum and maximum values of the number of recordings obtained per participant, as well as the mean and standard deviation of the motivation index.

In order to study the correlations between the three variables, and given that the total number of recordings obtained across all participants is excessive (5329 recordings) and might lead to overestimates, we took a random sample comprising $10 \%$ of the total (532 recordings). For this number the results were as follows: $r_{2-3}=.339, r_{2-4}=.748, r_{3-4}=.281(p<.01)$. The alpha value of the scale for this sample was .729 , the F statistic being significant $(F(2.532)=141.538, p<.001)$.

A simple plot of the time series obtained revealed their degree of irregularity. By way of example Figure 1 (lefthand side) shows three cases to illustrate this fact. Given the irregularity of the series these line graphs do not tell us whether these series show any pattern, and this is why recurrence plots are useful to reveal any hidden patterns in the data. Figure 1 (right-hand side) shows three recurrence plots corresponding to the same cases, and it can be seen how this procedure is useful for revealing different dynamics. The first case (number 6) yields a recurrence plot in which the absence of any pattern characteristic of random dynamics is shown. The second case (number 9) shows a structure with the typical lines parallel to the main diagonal, indicative of chaotic dynamics. And finally, the third case (number 41) reveals a structure in which the points of the dynamic are concentrated into very few areas of the space, characteristic of linear dynamics.

Analysing all the cases a summary of the results obtained from the recurrence plots is given in Table 2. The different patterns found were linear (regular dynamics), chaotic (nonlinear and deterministic dynamics) and random. The term 'Nonlinear or random' was used to label those plots without a clear pattern which enabled

Table 1

Descriptive statistics for the series obtained considering all the participants

\begin{tabular}{lcccc}
\hline & Minimum & Maximum & $M$ & $S D$ \\
\hline Number of recordings & 100 & 136 & 111.02 & 9.51 \\
Mean motivation index & 50.39 & 98.28 & 75.01 & 12.33 \\
Standard deviation of motivation index & 3.66 & 39.00 & 15.33 & 8.06 \\
\hline
\end{tabular}



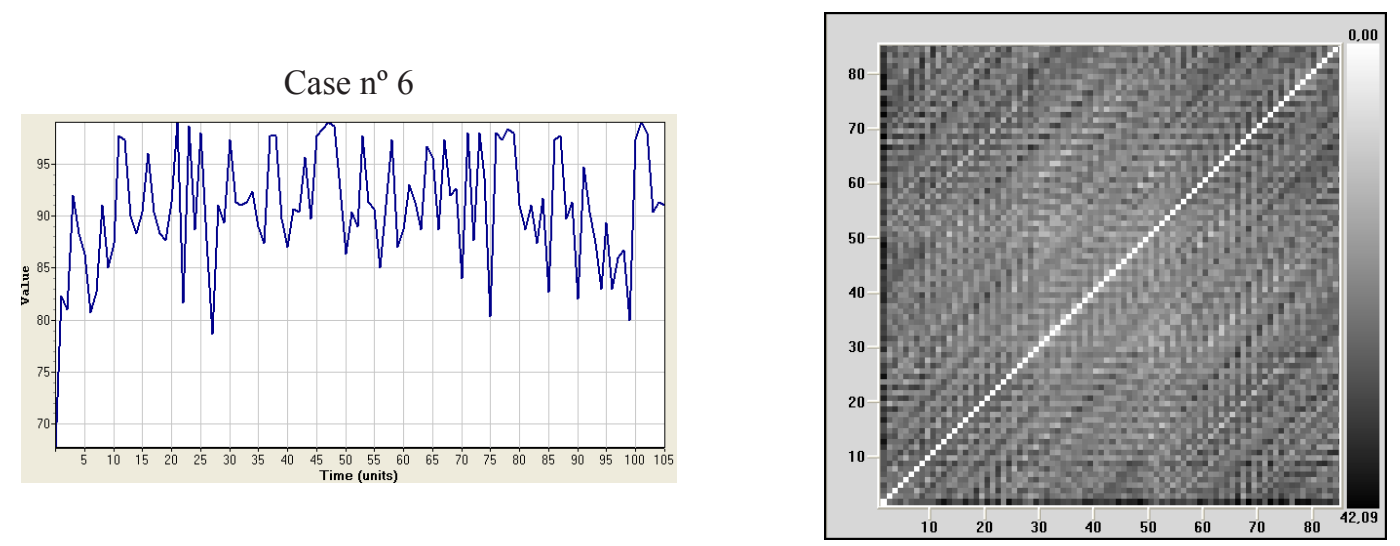

Case $n^{\circ} 9$
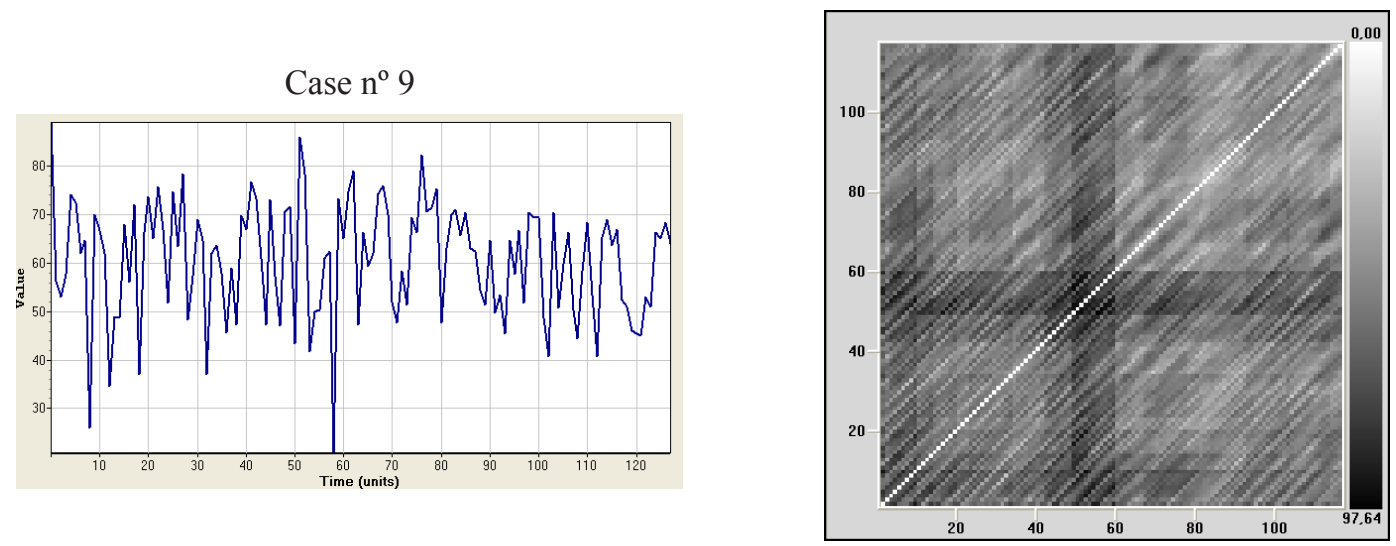

Case $n^{\circ} 41$
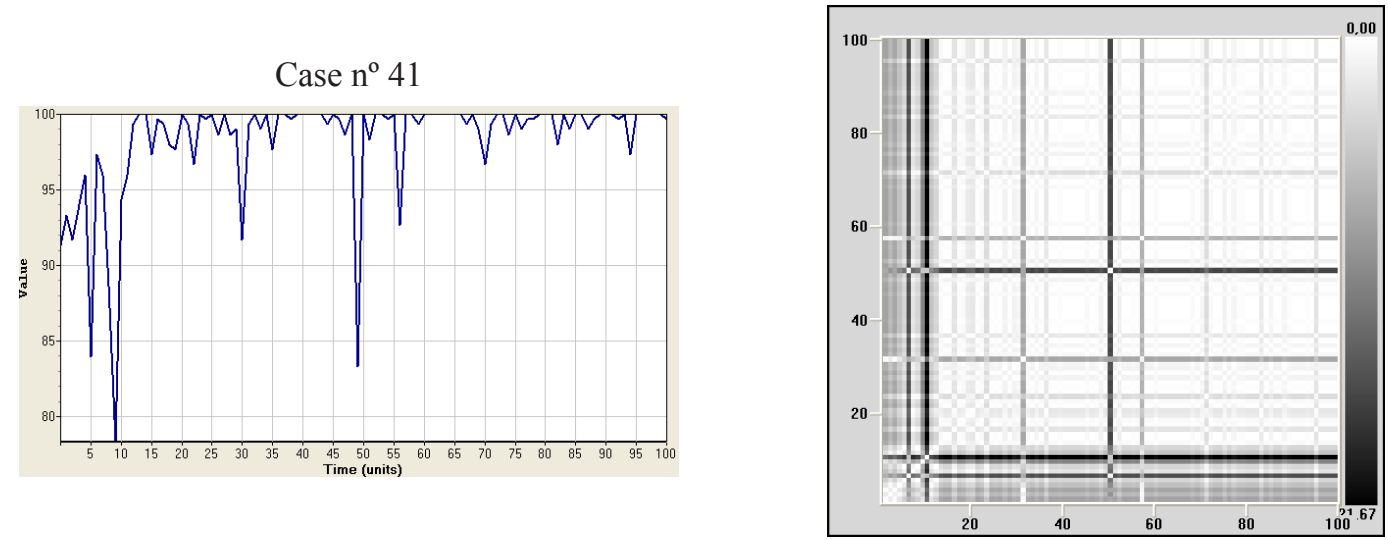

Figure 1. Line graphs (left) and recurrence plots (right) from different participants. 
Table 2

Types of dynamics found according to different analytic procedures

\begin{tabular}{lcccccc}
\hline & \multicolumn{2}{c}{ Recurrence plot } & \multicolumn{2}{c}{ Lyapunov exponents } & \multicolumn{2}{c}{ Surrogate data } \\
& $\%$ & $\mathrm{~N}$ & $\%$ & $\mathrm{~N}$ & $\%$ & $\mathrm{~N}$ \\
\hline Linear & $2.08 \%$ & 1 & $2.08 \%$ & 1 & & $\mathrm{NA}$ \\
Nonlinear or Random & $20.83 \%$ & 10 & & $\mathrm{NA}$ & & \\
Chaotic & $70.83 \%$ & 34 & $87.5 \%$ & 42 & $87.5 \%$ & 42 \\
Random & $6.25 \%$ & 3 & $10.41 \%$ & 5 & $12.5 \%$ & 6 \\
Total of series & $100 \%$ & 48 & $100 \%$ & 48 & $100 \%$ & 48 \\
\hline
\end{tabular}

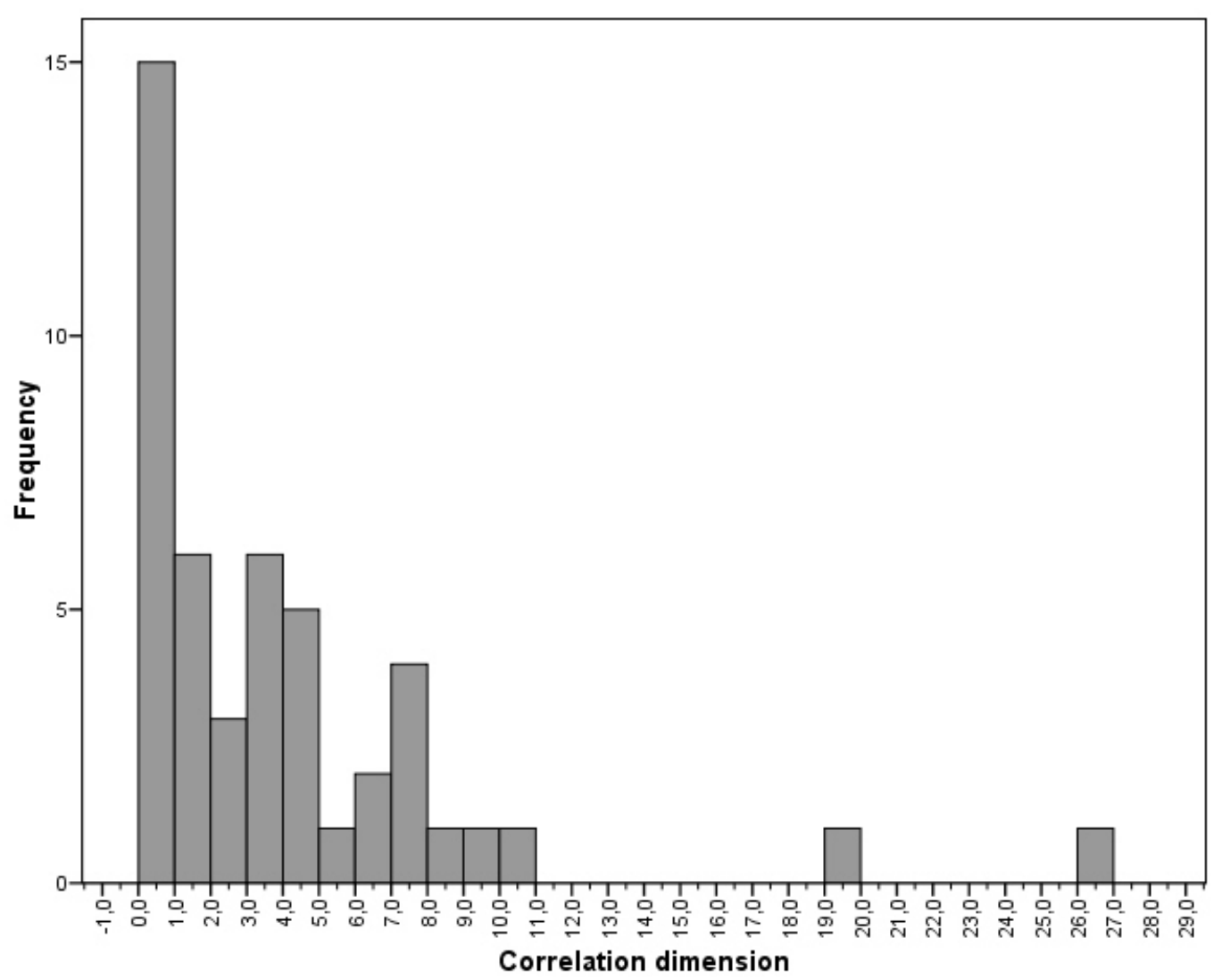

Figure 2. Histogram of values of correlation dimension.

a distinction to be made between chaotic and random dynamics. Table 2 also shows the results for the type of dynamic as calculated using Lyapunov exponents and surrogate data. Both analyses include cells labelled as 'NA' (not applicable) as the specific analysis does not enable these types of dynamic to be studied.

Taken together, the three types of analysis (recurrence plots, Lyapunov exponents and surrogate data) show that the predominating dynamics are chaotic in $70-80 \%$ of cases.

The results obtained from calculating the correlation dimension for each series are shown in the histogram of values in Figure 2. Except for a few very high values (above 8 or 10) that correspond to those cases with random dynamics the correlations dimensions are generally low, as would be expected with chaotic dynamics. Selecting the series that showed chaotic dynamics according to the 
previous analyses (recurrence plots, Lyapunov exponents and surrogate data) we obtained a mean value for the correlation dimension of $3.350(S D=3.929)$, this being a clear indicator of low dimensionality.

\section{Discussion}

The results of this study enable conclusions to be drawn in three highly important areas of organisational behavior, namely with regard to epistemological and methodological (research) aspects and in terms of management (intervention).

\section{Epistemological repercussions}

As regards epistemology the results obtained show that the dynamics of work motivation are highly irregular, this being illustrated in visual terms by the line graphs (see Figure 1). Alongside this, the high degree of deterministic chaos (in $75 \%$ of cases) provides substantive empirical evidence in support of the idea that the universality of this type of behavior extends to the organisational field, as has been previously argued by several authors (Cheng \& Van de Ven, 1996; Guastello et al., 1998; Guastello et al., 1999; Navarro et al., 2007; Richards, 1990; Woyshville et al., 1999). More specifically, the present study provides useful information that lends more precise support to the findings of Guastello et al. (1999) and Navarro et al. (2007), namely that the dynamic study of work motivation reveals the chaotic nature of this phenomenon.

With respect to the above the values of the correlation dimension $(M=3.550$ and $S D=3.929)$ also indicate low dimensionality, this being a clear illustration that the chaotic dynamics found are being determined by a small number of variables. According to these data no more than three or four variables would be required to explain the dynamics of work motivation. This finding is in stark contrast to some of the recommendations put forward by experts with the aim of bolstering research in this field, especially the notion that a more comprehensive understanding of the nature and behavior of this phenomenon requires mega-models of motivation developed from a large number of potential explanatory variables (Locke \& Latham, 2004). However, it would seem that what is needed are simple models in which a few variables interact with one another in a nonlinear way and generate complex behaviors such as sensitive dependence on initial conditions or unpredictability, both of which are characteristic of chaotic dynamics.

We also found random dynamics in work motivation (around $25 \%$ of the cases analysed). Although, in principle, these dynamics cannot be subjected to scientific analysis it would be interesting to conduct more detailed combined studies of chaotic and random dynamics with the aim of detecting possible correlates between the two and identifying variables that might explain their appearance. Similarly, in terms of the different patterns found it would be important to investigate those variables which may account for their emergence, as this would enable a distinction to be made between different etiologies.

\section{Methodological repercussions}

At the methodological level we believe that one of the strengths of the present study is that it conducted a systematic recording of the behavior of work motivation over a long period of time and in a naturalistic context; this was possible thanks to the experiential sampling enabled by use of the diary technique. This is a key aspect if our aim is to characterise the dynamics of work motivation; indeed, several authors have called for the systematic incorporation of the time factor into research and argue that this is vital in order to deepen and advance our knowledge of this aspect of human life. As Katzell argued more than fifteen years ago "Paying more attention to consistencies and changes over time contributes to a better understanding of various subjects of interest, and thereby to more effective ways of dealing with them" (Katzell, 1994: 8).

The fact that motivation behaves chaotically in $75 \%$ of cases in our study is confirmation that when this phenomenon is analysed longitudinally and dynamically the results obtained differ substantially from those found when using cross-sectional designs based on synchronic measures. Moreover, when one considers that linear behavior was only exceptionally observed ( 1 case of 48 analysed, equivalent to $2.08 \%$ ), questions must be raised about the value of continuing to rely exclusively on techniques developed to analyse linear behavior (for example, correlations, analysis of variance, linear regression, structural equation models, etc.), as occurs in most of the research conducted in the field. If motivation is a chaotic process, and according to our results this is so in the majority of cases, then studying it using cross-sectional designs and the abovementioned analytic techniques will provide little more than a rough sketch compared to what might be achieved using other procedures. In sum, a highly reductionist body of knowledge is being generated about an object of study that we know to be complex and which presents one of the basic characteristics of complex systems: chaoticity (cf. Munné, 2005).

With respect to previous studies of the chaotic nature of various phenomena in different areas of organisational behavior, the present research adds the use of classical analytic tools to the study of nonlinear systems; these tools are the calculation of the optimum values of the lag and the embedding dimension, the use of recurrence plots, the calculation of Lyapunov exponents using an algorithm 
that is particularly well-suited to short time series, the calculation of the correlation dimension and comparison using surrogate data. The use of this set of techniques also enabled a significant step forward to be taken with respect to previous studies of the chaotic dynamics of work motivation, as the results obtained here were consistent with the types of analyses performed.

In addition, it should be noted that the present study may also reveal a methodological limitation concerning a certain sampling bias due to the demands of the task required of participants (completing a diary several times a day over a period of almost one month). Given these demands it is difficult to persuade poorly motivated people to take part in such a study, and if they do it is likely that their level of commitment will fall short of that required to complete the necessary recordings. We believe that this assumption is lent support by the fact that the mean score on the motivation index was 75.01 out of 100 (see Table 1).

Another possible limitation in our study is the use irregular time intervals. We have developed a design and have done similar analysis to previous research developed by Richards (1990), Cheng and Van de Ven (1996), Woyshville, Lackamp, Eisegart and Gilliland (1999) and Navarro, Arrieta and Ballén (2007). Our results are also consistent with the research conducted by Guastello, Johnson and Rieke (1999) that used regular intervals. On the other hand, and Heath (2000) has discussed about this, using random signals should increase the number of cases presenting a random pattern as opposed to increasing the number of cases presenting nonlinear (chaotic) patterns.

\section{Repercussions for management}

As regards the third area, that of management the results obtained here would also appear to be of relevance to the interests of managers and executives. The management tools commonly used to influence employee motivation (for example, management by objectives, remuneration and compensation systems, job enrichment, etc.) are usually based on classical theories (goal-setting theory, theory of needs, etc.) that have not proven particularly sensitive to the evolving nature of work motivation or the influence which time has on it.

The results of the present study show that work motivation is a process that undergoes constant change over time and it should thus be considered as such, rather than as something stable and atemporal. Therefore, it is important that managers also adopt a perspective that is consistent with the nature of this phenomenon, and that they ask themselves how motivation evolves and how it may change among employees. From such a vantage point one would expect to find discontinuities and changes in motivation, and it would be no surprise to discover that what motivated employees yesterday fails to do so today. It would also no longer seem strange that the same management tools produce different effects when applied at different times to the same people, or when applied at the same time to different people. The upshot of all this is that one has to remain alert to the three basic characteristics of dynamic systems: their discontinuities, the constant feedback produced by interchange and the non-proportionality which results from nonlinearity.

The fact that motivation shows chaotic dynamics has two important consequences in terms of management options. Firstly, we know that these dynamics are deterministic, that is to say, they follow laws and patterns of behaviors over which we can have a significant influence. Moreover, such influence does not require intervention in a countless number of variables; on the contrary, it can be achieved by managing very few variables or elements. This does not mean that we can be sure about which specific elements are susceptible to intervention, but we do know - and this in itself is an important piece of data - that we will only need to intervene in a few elements. Secondly, we know that the dynamics are also unpredictable, in other words, we can never be sure in advance what the final outcome of an intervention will be. For the world of management, which is geared mainly toward control and prediction, this aspect could arouse feelings of despair and impotence. However, disciplines such as psychology or sociology have repeatedly shown that human behavior cannot simply be controlled at will. And there is no reason why work motivation should be any exception.

In our view this management paradox (being able to influence motivated behavior but not control it) should not be taken as an insurmountable obstacle in the face of which managers opt to do nothing. Of course, a failure to take action is in itself a way of (not) intervening in motivation and, inevitably, this will follow its course. In light of this we believe that managers need to give up the search for standard recipes and accept that continuous learning, the fruit of one's own learning and of learning from others, is the only way of increasing our knowledge of the dynamic nature of work motivation. Case studies and the management experiences of colleagues could be a good source of such learning, and perhaps this is why knowledge management practices play such a key role in management today.

In sum, management faces a stiff challenge, one which will only be properly addressed by adopting attitudes that foster at least three things: the constant questioning of our own preferred intervention models; an openness to change when the situation requires it; and a willingness to design and use flexible management tools that are consonant with the equally flexible and changing nature of work motivation. 


\section{References}

Abraham, F. D. \& Gilgen, A. R. (Eds.). (1995). Chaos theory in psychology. Westport, CT: Prager Publishers.

Ancona, D. G., Goodman, P. \& Tushman, M. (2001). Time: a new research lens. Academy of Management Review, 26(4), 645-663.

Ancona, D. G., Okhuysen, G. \& Perlow, L. (2001). Taking time to integrate temporal research. Academy of Management Review, 26(4), 512-529.

Arthur, W. B. (1999). Complexity and the Economy. Science, 284, 107-109.

Bahrami, B., Seyedsadjadi, R., Babadi, B. \& Noroozian, M. (2005). Brain complexity increases in mania. Neuroreport: For Rapid Communication of Neuroscience Research, 16(2), 187-191.

Bandura, A. (1997). Self-efficacy: the exercise of control. New York: Freeman.

Belaire-Franch, J. \& Contreras, D. (2002). Recurrence plots in nonlinear time series analysis: free software. Journal of Statistical Software, 7(9), 1-18.

Bolger, N., Davis, A. \& Rafaeli, E. (2003). Diary methods: Capturing life as it is lived. Annual Review of Psychology, 54, 579-616.

Cheng, Y. T. \& Van de Ven, A. H. (1996). Learning the innovation journey: Order out chaos? Organization Science, 7(6), 593614.

Csikszentmihalyi, M. (1990). Flow: The psychology of optimal experience. NY: Harper and Row Publishers.

Cvitanovic, P. (1989). Universality in chaos (2nd ed.). Bristol: Adam Hilger.

Dalal, R. S. \& Hulin, C. L. (2008). Motivation for what? A multivariante dynamic perspective of the criterion. In R. Kanfer, G. Chen \& R. Pritchard (Eds.), Work motivation. Past, present and future (pp. 63-100). New York: Routledge.

Dechert, W. D. (Ed.). (1996). Chaos theory in economics. Methods, models and evidence. Cheltenham, UK: Edward Elgar Publishing.

Eidukaitis, A., Varoneckas, G. \& Zemaityte, D. (2004). Applications of chaos theory in analyzing the cardiac rhythm in healthy subjects at different sleep. Human Physiology, 30(5), 551-555.

Fried, Y., \& Slowik, L.H. (2004). Enriching goal-setting theory with time: an integrated approach. Academy of Management Review, 29(3), 494-422.

George, J. M. \& Jones, G. R. (2000). The role of time in theory and theory building. Journal of Management, 26(4), 657-684

Grassberger, P. \& Procaccia, I. (1983). Characterization of strange attractors. Physical Review Letters, 50, 346-349.

Guastello, S. J. (1998). Creative problem solving groups at the edge of chaos. Journal of Creative Behavior, 32(1), 38-57.

Guastello, S. J. (2002). Managing emergent phenomena: Nonlinear dynamics in work organizations. Mahwah, NJ: Lawrence Erlbaum Associates.
Guastello, S. J., Hyde, T. \& Odak, M. (1998). Symbolic dynamic patterns of verbal exchange in a creative problem solving group. Nonlinear Dynamics, Psychology, and Life Sciences, 2(1), 35-58.

Guastello, S. J., Johnson, E. A. \& Rieke, M. L. (1999). Nonlinear dynamics of motivational flow. Nonlinear Dynamics, Psychology, and Life Sciences, 3(3), 259-273.

Guastello, S. J., Koopmans, M. \& Pincus, D. (Eds.) (2009). Chaos and complexity in psychology: Theory of nonlinear dynamical systems. New York: Cambridge University Press.

Heath, R. A. (2000). Nonlinear dynamics. Techniques and applications in Psychology. Mahwah, NJ: Lawrence Erlbaum Ass.

Hegger, R., Kantz, H. \& Schreiber, T. (1999). Practical implementation of nonlinear time series methods: The TISEAN package. Chaos, 9(2), 413-435.

Kanfer, R. (1990). Motivational theory and indutrial and organizational psychology. In M. Dunnette \& L. M. Hughs (Eds.), Handbook of Industrial and Organizational Psychology (pp. 75-170). Palo Alto, CA: Consulting Psychologist Press.

Kaplan, D. \& Glass, L. (1995). Understanding nonlinear dynamics. New York: Oxford University Press.

Katzell, R. A. (1994). Contemporany meta-trends in industrial and organizational psychology. In H. C. Triandis, M. Dunnette \& L. M. Hughs (Eds.), Handbook of Industrial and Organizational Psychology (pp. 1-89). Palo Alto, CA: Consulting Psychologist Press.

Locke, E. A. \& Latham, G. P. (2004). What should we do about motivation theory? Six recommendations for the twenty-first century. Academy of Management Review, 29(3), 388-403.

Lorenz, E. N. (1995). La esencia del caos [The esence of chaos]. Madrid: Debate. (Original work published 1993).

Masterpasqua, F. \& Perna, P. A. (Eds.). (1997). The psychological meaning of chaos. Washington: APA.

Mathews, K. M., White, M. C. \& Long, R. G. (1999). Why study the complexity in the social sciences? Human Relations, 52(4), 439-462.

McGrath, J. E. \& Kelly, J. R. (1986). Time and Human Interaction. New York: Guilford Press.

McGrath, J. E. \& Tschan, F. (2004). Temporal matters in social psychology. Examining the role of time in the lives of groups and individuals. Washington, DC. APA.

Mitchell, T. \& James, L. (2001). Building better theory: Time and the specification of when things happen. Academy of Management Review, 26(4), 530-547.

Mosakowski, E. \& Earley, P.C. (2000). A selective review of time assumptions in strategy research. Academy of Management Review, 25(4), 796-812.

Munné, F. (2004). El retorno de la complejidad y la nueva imagen del ser humano: Hacia una psicología compleja [The return of complexity and the new image of human being: towards a complex psychology]. Revista Interamericana de Psicología, 38(1), 21-29. 
Munné, F. (2005). ¿Qué es la complejidad? [What's complexity?]. Encuentros de Psicología Social, 3(2), 6-17.

Navarro, J., Arrieta, C. \& Ballén, C. (2007). An approach to the study of dynamics of work motivation using the diary method. Nonlinear Dynamics, Psychology, and Life Sciences, 11(4), 473-498.

Pentland, W. E., Harvey, A. S., Lawton, M. P. \& McColl, M. A. (1999). Time use research in social sciences. New York: Plenum Press.

Pincus, D. (2001). A framework and methodology for the study of nonlinear, self-organizing family dynamics. Nonlinear Dynamics, Psychology, and Life Sciences, 5(2), 139-173.

Richards, D. (1990). Is strategic decision making chaotic? Behavioral Science, 35, 219-232.

Robertson, G. P. \& Combs, A. (Eds.). (1995). Chaos theory in psychology and the life sciences. Mahwah, NJ: Lawrence Erlbaum Ass.

Roe, R.A. (2005a). No more variables, please. Giving time a place in work and organizational psychology. In H. Kepir Sinangil, F. Avallone y A. Caetano (Eds.). Convivence in Organizations and Society (pp. 11-20). Milano: Guerini.

Roe, R.A. (2005b). Studying time in organizational behavior (on line). Maastricht Research School of Economics of Technology and Organization. Research Memoranda, number 048. (Retrieved March 21, 2009). Available in: http://edocs. ub.unimaas.nl/loader/file.asp?id=1120.

Rosenstein, M. T., Collins, J. J. \& De Luca, C. J. (1993). A practical method for calculating largest Lyapunov exponents from small data sets. Physica, 65(D), 117-134.

Russo, P. V. \& Mandell, A. J. (1983). Metrics from nonlinear dynamics adapted for characterizing the behavior of nonequilibrium enzymatic rate functions. Anals of Biochemistry, 139, 91-99.

Scollon, C., Diener, E., Oishi, S. \& Biswas-Diener, R. (2005). An experience sampling and cross-cultural investigation of the relation between pleasant and unpleasant affect. Cognition and Emotion, 19(1), 27-52.
Schreiber, T. \& Schmitz, A. (2000). Surrogate time series. Physica D, 142(3-4), 346-382.

Stajkovic, A. \& Luthans, F. (1998). Self-efficacy and workrelated task performance: A meta-analysis. Psychological Bulletin, 124(2), 240-261.

Stam, C. J. (2005). Nonlinear dynamical analysis of EEG and MEG: Review of an emerging field. Clinical Neurophysiology, 116(10), 2266-2301.

Steers, R. M., Mowday, R. T. \& Shapiro, D.L. (2004). The future of work motivation theory. Academy of Management Review, 29(3), 379-387.

Tsonis, A. R. (1992). Chaos. From theory to applications. New York: Plenum Press.

Vallacher, R. R. \& Nowak, A. (Eds.). (1994). Dynamical systems in social psychology. San Diego. CA: Academic Press.

Vroom, V. H. (1964). Work and motivation. New York: Wiley.

Weber, B.A. \& Beverly, R. (2000). Data collection using handheld computers. Nursing Research, 49(3), 173-175.

Williams, K. J., Donovan, J. J. \& Dodge, T. L. (2000). Selfregulation of performance: Goal establishment and goal revision processes in athletes. Human Performance, 13, 159-180.

Wolf, A., Swinney, H. L. \& Vastano, J. A. (1985). Determining Lyapunov exponents from a time series. Physica, 16D, 285-317.

Woyshville, M.. J., Lackamp, J. M., Eisegart, J. A. \& Gilliland, J. A. M. (1999). On the meaning and measurement of affective instability. Clues from chaos theory. Biological Psychiatry, 45(3), 261-299.

Yeragani, V. K., Rao, K. A., Smitha, M. R., Pohl, R. B., Balon, R. \& Srinivasan, K. (2002). Diminished chaos of heart rate time series in patients with major depression. Biological Psychiatry, 51(9), 733-744.

Received October 24, 2008

Revision received April 28, 2009 Accepted May 23, 2009 